\title{
The Sexualization of Menstruation: On Rape, Tampons, and 'Prostitutes'
}

\author{
Lacey Bobier
}

Menarche is a pivotal event in the development of one's sexuality. For girls, it marks a transition from childhood (culturally constructed as asexual), to womanhood (a sexualized, objectified other). Bodies become sexually marked through reproductive potential and observable pubertal developments. Research has shown that girls experiencing menarche celebrate this transition (Fingerson 2006; Lee 2009). These same studies have shown that girls rarely make the connection between menstruation and reproduction or sexuality (Fingerson 2006) and, when they do, react negatively to this association (Lee 2009).

Previous studies have relied on surveys, short-answer questionnaires, or written narratives (see Brooks-Gunn and Ruble 1982; Morse and McKinnon Doan 1987; Koff and Rierdan 1995; Moore 1995; Schooler et al. 2005), and are thus limited by the researchers' interpretations. Work using interviews has often accessed post-adolescent populations (see Lee 1994; Beausang and Razor 2000), thereby relying on reconstructed narratives that may not accurately depict thought processes as they occur during the early years of menstruation; initial understandings are likely reinterpreted in light of later accumulated experiences. Janet Lee (1994) found some evidence linking menarche and sexuality that relied on narratives from interviewees ages eighteen to eighty. Finally, many important texts in this literature pre-date the turn of the century. Margaret Stubbs and Ingrid Johnston-Robledo (2013) explored how the phenomenon of the sexualization of girls might affect girls' experiences of menstruation. Given that studies on the sexualization of girls emerged in the early nineties, corresponding with the increasing cultural presence of the process itself, the fact that few salient studies postdate this era may offer some insight into why themes of sexuality have not been prominent. 
Adolescent girls raised in this cultural context may be more likely to highlight the sexual dimension of menses.

Though gender scholars debate the difference between sex and gender, theorists have argued that sex, rather than being a "naturally" determined biological fact, is socially constructed (see Kessler 1990; Anne Fausto-Sterling 2000). A substantial portion of such work draws on cases of intersex individuals to elucidate how one's supposedly biological sex can, in fact, be based on cultural definitions of the gender categories man and woman (see, for example, Kessler 1990; Anne Fausto-Sterling 2000). This literature shows that central to the definition of "female" is reproductive potential (Anne Fausto-Sterling 2000) and, therefore, menarche and menstruation. For this reason, sex and gender blur when discussing menstruation. Consequently, I chose to interchange the terms female and woman, referring to one sex/gender category for the sake of this paper. Despite my terminology here, it is important to recognize that many people born with "female" physiology do not identify as women. Moreover, many people born without this physiology do identify as women. However, the sample of this study is comprised of women-identified "females" and maintains a focus on this population, though the findings have implications for the aforementioned groups to be explored by future research.

The extant research concerning young adolescents and menarche have primarily concerned attitudes, knowledge, preparation, and outcomes. Though pre- and post-menarcheal girls have reported that they feel/felt prepared for menarche (Morse and McKinnon Doan 1987; Koff and Rierdan 1995b), studies have shown that both groups lack cognitive knowledge about the physiological process and subjective, experiential knowledge (Brooks-Gunn and Ruble 1982; Koff and Rierdan 1995a; Moore 1995; Fingerson 2006). Preparation for menstruation positively corresponds to more positive attitudes and experiences of menarche (see Rierden 1983; McPherson and Korfine 2004). However, even these girls associated menarche and menstruation with ambivalent and negative sentiments (Koff and Rierdan 1995b). They saw menstruation as something embarrassing, dirty, and gross, and experienced resulting shame and anxiety (Ruble and Brooks-Gunn 1982; Morse and McKinnon Doan 1987; George and Murcott 2011; Lee 1994; Moore 1995; Kissling 1996). These feelings largely stem from societal taboos concerning female bodily processes and sexuality, the corresponding medicalization, and the consequent pressure to sanitize and conceal these functions, including the supposed hygienic crisis that is menstruation (Brumberg 1997). The most frequently mentioned positive reaction to menstruation was a sense of maturity (Ruble and Brooks-Gunn 1982; Morse and McKinnon Doan 1987; Moore 1995). The framework of menarche as instrumental to the transition to womanhood provides context for the development of associations between menarche and sexuality.

Other studies exploring girls' thoughts at this developmental stage provide further reason to suspect they may connect menarche and sexuality. Research 
relates physical evidence of pubertal developments, specifically in the form of breast growth, to girls' awareness of increased attention to their bodies, alterations in responses to their bodies and behaviors, and discomfort with these reactions (Martin 1996; Summers-Effler 2004). This increased bodily awareness and discomfort could easily translate into and parallel feelings that accompany the transition in social and sexual standing that menarche signifies. Accordingly, Lee (2009) explained that, at the time of menarche, the several participants in her study who did connect menarche to sexual maturation "felt disempowered by the way people were starting to look and relate to them" $(622)$. This sentiment likely reflects the process of sexual objectification.

Sexual objectification occurs when women are reduced to and treated as bodies, specifically, bodies intended for use and consumption by others (Fredrickson and Roberts 1997). Self-objectification involves the internalization of an outsider's view of one's body, or judging bodily attractiveness and value through an external lens, and the resulting treatment of oneself as an object to be viewed and evaluated (Martin 1996; Fredrickson and Roberts 1997). Self-objectification is deeply tied to menarche as the onset of menstruation is linked with a transition to the sexual and reproductive realm (Lee 1994). Girls also begin the process of self-objectification at puberty because their bodies become more overtly sexual and, thus, sexualized and objectified by others (Thorne 1994; Martin 1996). Accordingly, women are especially at risk of adopting an observer's perspective of their body during times of physiological change, such as the onset of menstruation (Fredrickson and Roberts 1997).

Moreover, as Karin Martin (1996) indicated, while girls may not consistently make explicit links between intercourse, sexuality, and menstruation, puberty and sexuality are intertwined, and parents and teachers often present information that contain a sexual subtext, intentionally or not. The fact that menstruation is normally incorporated into sex education classes underscores this point.

While Martin (1996) found that her female interviewees connected menarche to pregnancy and sex, few have replicated this discovery. As recently as 2006, Fingerson found that her interviewees only connected menstruation to reproduction (and sexuality) when asked to explain the purpose of menstruation. This finding is consistent with previous research that revealed girls did not spontaneously reference reproduction in connection to menstruation (Ruble and Brooks-Gunn 1982; Koff and Rierdan 1995b). Havens and Swenson's (1988) review of educational advertisements resulted in the discovery that only three of thirty-one videos on menstruation mentioned the relationship between menstruation and reproduction in the form of the relationship between tampons and virginity. Stubbs and JohnstonRobledo further discovered that mothers, a primary source of information on menses (Whisnant and Zegans 1975; Havens and Swenson 1988; Koff and Rierdan 1995a, 1995b; Moore 1995; Kissling 1996; Beausang and Razor 2000), failed to contemplate the relationship between the sexualization of girls 
and their daughters' pubertal development. These same authors hypothesized a possible connection between sexuality and girls' attitudes toward menstruation, suggesting that girls might embrace menstrual suppression as a way to self-sexualize and reject the menstruating body that is incompatible with the sexualized ideals to which girls are encouraged to aspire.

Despite sparse evidence that adolescent girls link menarche, menstruation, and sexuality, themes concerning maturational development, indicated that girls may yet make associations between these topics and experiences. Following Stubbs and Johnston-Robledo, I expected millennials to have incorporated sexuality into their understandings and experiences with menstruation more so than previous generations. Since the late 1980s, research has found that girls are sexualized in a myriad of ways including sexualized portrayals in media and representation in merchandise, parental messages concerning the primary importance of appearance, peer policing, self-sexualization through adherence to these standards and, at the extreme, sexual assault, abuse, traffic, and prostitution (Zurbriggen et al. 2007). This corresponds to a moral panic in which parents and news media depict certain media outlets as inappropriately positioning girls as "sexy," while consumer culture targets increasingly younger audiences, supposedly robbing them of their innocence and leading to future promiscuity (Egan 2013). In opposing the sexualization of girlhood there is an increasing emphasis on innocence and purity via virginity (Valenti 2009). Such concerns may heighten the awareness of the sexual implications surrounding girls' change in menstrual status.

I chose to interview young adolescent girls as they offered a unique lens to understand the process of developing sexual subjectivity as it occurs. By looking at this moment, we can see how girls navigate various discourses and cultivate the language to represent their thoughts. Because these girls lack the vocabulary to describe their relationship with menstruation, they are less able to articulate their understanding of menses. We can appreciate how they unpack ideas as girls interpret menstruation through frameworks they have developed separate from formal discourses. This led me to ask: What meanings do girls attach to menstruation and menarche? Do they see menstruation as related to sexuality, explicitly or implicitly? How do they navigate the various meanings?

\section{The STUdy}

\section{Methods}

I interviewed ten middle school girls ages eleven through thirteen, recruited from three private middle schools in Michigan that were comprised primarily of white, middle to upper middle-class pupils. My sample reflected these statuses, though one student identified as African American. All but one girl was post-menarcheal. The median age of onset was eleven (SD: 1.5 years), with the youngest being nine, and the oldest thirteen. 
Two schools had small student bodies ( $<30$ girls each), were coed and had liberal atmospheres. One was single-sex, conservative, larger, and affiliated with the Catholic Church. Originally, I thought the contrasting liberal and conservative bents might manifest in my findings, however, there was little variation by school. This consistency is something to be further explored in future research, along with the roles of class and race variation (my sample, lacking in diversity, cannot speak to these factors of potential import).

Recruitment involved a mix of introducing myself and my research to the student body, distributing informational letters for the girls and their parents in person and via email (these letters were accompanied by consent forms for the parents, assent forms for the girls, and a short questionnaire on the students' backgrounds). For the conservative school, recruitment ultimately turned into snowball sampling as a girl from one social group participated, and her friends followed. This may have affected my findings as friends may share opinions. The topic of my research likely limited my sample size as some girls relayed that others were too embarrassed to participate and/or their parents had refused to consent.

Before interviews, girls were asked to complete questionnaires with their parents. This form included questions concerning: age; grade; socioeconomic status; religion; the number and gender of siblings; the number of years they had attended their current school; and race/ethnicity. Interviews occurred one-on-one in available classrooms or offices. The familiar setting, combined with the privacy of the locations, allowed the girls to feel more relaxed. Interviews ranged from half an hour to an hour and fifteen minutes; most lasted around an hour. Interviews began with conversation to build rapport (about girls' athletic activities, summer plans, et cetera.), followed by a quick preface concerning topics the discussion might cover and students' rights as participants. With the approval of the Institutional Review Board, all interviews were audiotaped, and interviews and questionnaires were transcribed. Identifiers were removed from transcriptions, participants were assigned pseudonyms, and schools given aliases. The interviews were coded inductively.

I performed semi-structured interviews for which I came prepared with a list of questions, though the girls often answered my questions without my prompting. Interview questions covered a range of topics including: introductions to the subject of menstruation; the roles of friends, siblings, boys, schools, parents, the medical establishment, the internet, books, and the media; the biological process of menstruation; feminine hygiene products; symptomatology; age of menarche; menstrual suppression; managing menstruation; and (dis)likes concerning the menstrual experience. I also offered a scripted anecdote concerning menstruation hoping girls would respond with their own stories.

Aware that my questions broached awkward topics, I carefully monitored my self-presentation, attempting to appear in a way that would warrant the respect, and, thus, cooperation of school administrators, without alienating my interviewees. I hoped my youthful look and demeanor would lead 
the girls to view me as a near-peer in whom they could confide. Given the intimate details the girls disclosed, I believe I succeeded in earning their trust. When asking a participant at the end of our session to please send her friends my way, she responded, "definitely, I'll tell my friends about the cool college lady researching PMS."

Because of the demographics of my sample, as well as the fact that participation was voluntary, the sampling involved in this project is not representative. These factors, as well as the size of my sample, limit the generalizability of my data. However, the consistency of my findings across all three schools would indicate that the trend of the sexualization of menstruation extends beyond my sample.

\section{Findings}

\section{Tampons, the Fear of "Down There," and "Waiting Until You Are Ready"}

As in previous studies, my interviewees referenced reproduction and sexuality when asked about the purpose of menstruation. However, this sample of girls stood out in the way they interwove these topics throughout the entire interviews. A quintessential example occurred when I asked Sophia (11, white) how she felt about commercials for feminine hygiene products and she went on to describe how commercials for Trojan condoms made her feel uncomfortable. This incident highlights a salient dimension of this association between menarche and sexual development during these interviews: girls experienced this terrain with anxiety and trepidation. This is evident in the way participants explained their reasons for avoiding or delaying the use of tampons. All but one of my interviewees regularly employed pads instead of tampons, but would occasionally make exceptions when they wanted to swim. For instance, when asked whether she had ever used a tampon, Isabella (13, white) explained that:

The problem is, I'm a full-time swimmer, so I didn't want to use a tampon, but eventually I had to ... like my first time, at the end of the week, it [the menstrual flow] was really light. I barely needed one but I did [use a tampon] just in case. It took a few tries [to insert it] and it wasn't really right... I was like freaking out ... I freaked out because sticking something in [the vagina] was creepy.

Isabella's terminology was characteristic of these stories. Other standard words and phrases included: "awkward;" "uncomfortable;" and "scary." For all of the participants, this experience made a lasting impression. They were able to recount, in detail, where they were, who was with them, what was said, even what brands were chosen. This moment was powerful because it was the first time they had explored, as Emma (12, white) and Olivia (13, white) were prone to say, "down there." This discomfort was amplified 
by the fact that many of them did not actually know where to put the tampon or the proper anatomical terminology. Olivia elaborated by stating that "you never really see it [the vagina] until you actually experience it." While these young girls considered these stories representative of a traumatic developmental moment, these memories will likely fade relative to other life experiences. This may be one reason such accounts have not appeared in previous studies that rely on retrospective accounts.

While previous research has framed fears surrounding tampons as resulting from lack of bodily knowledge (Martin 1996; Fingerson 2006) (which surely remains a contributing factor in this sample), my interviewees also consistently employed sexual language when narrating their thoughts of and experiences with tampons. Both indirectly and directly, my interviewees revealed that this experience was partly distressing because they were forced to confront (and, consequently, reject) their sexuality. The language used to frame their relationships with tampons reflected this confrontation. Girls explained how pads operated as place holders, something to help you adapt to menstruation without having to go "down there." My interviewees referred to pads as "starters" and unanimously agreed that one should wait to try tampons until "she is ready." Interestingly, the language used here is similar to phrases that surround the topic of first sex. Girls are relentlessly told to wait "until they're ready." Apparently, adolescent girls associate the penetration of the penis into the vagina with the insertion of a tampon. Girls define sex in phallocentric terms and, in this characterization, neglect numerous, non-penetrative forms of sexuality. For example, when questioned as to why one would avoid tampons, Sophia launched into a monologue about her sister's refusal to use tampons and how "that's kind of a good sign because [she] doesn't want anything to go in there." Here, Sophia associates tampons with phallocentric sexual activity.

Although the definition of "sex" has been and remains contested, one consistent definition concerns the penetration of a vagina by a penis (Maines 1999). Historically, many consider virginity to cease when the hymen is "broken"l (The Swedish Association for Sexuality Education). However, exercise itself can tear, thin or stretch the hymen (The Boston Women's Health Collective 2011) resulting in physical alterations before puberty. Tampons can also affect the structure (The Boston Women's Health Collective), which may further cement the association between tampons and sex for girls. Penetration is consistently associated with a particularly condemned form of sex for girls in this age group. In avoiding penetration girls are valuing virginity above all other sexualities.

While defending her choice to abstain from tampon usage, Madison (13, white) explained that:

It's scary, like, what if you put it in the wrong hole? . . . It's also like the idea of sex, which freaks me out because I don't like thinking of another person inside of me. It's just like, nope, that's a future Madison problem. I'm not going to think about that. It's just like this is so weird. So weird. 
Madison describes how she associates tampons with sexual penetration. In order to navigate her discomfort with the sexuality she sees as associated with menstruation, she employs a strategy which I refer to as the splintering of the self. Like the other girls in my study, Madison is adjusting to the idea of being a menstruating woman. For her, this is enough of a challenge. Trying to integrate a sexual aspect into her identity is, for the moment, too overwhelming. Thus, she splits herself into two different people: a girl/woman who has just reached menarche, and a future sexual woman. By assigning the latter to the future, she can focus on the present.

\section{The Splintering of the Current and Future Self}

This strategy of splintering was employed by many of the participants. Each girl assured me that she was not sexually active, yet most addressed the topic of a future sexually active self. They did not think it was necessary to "deal with it" presently and assigned that frightening duty to a future self. Splintering, and the intensity with which girls rejected the need to address their sexuality in the present, shows the extent to which adolescent girls are intimidated by and even afraid of their sexuality. Not yet ready to grapple with such issues, girls avoid things that might remind them of their sexuality (such as tampons).

\section{The Present Rejection of All Things Sexual: The Pill and Intercourse}

All but one girl vehemently asserted that they were not sexually active without any prompting from me. This relates back to Sophia applauding her sister for not "want[ing] anything in there." They were invested in the idea of the sexually innocent "good girl." Along with rejecting tampons, only one girl said she would consider using the pill to control cramps or extend time between cycles. Many feared that birth control pills could cause infertility, but even with the caveat of no harmful side effects, interviewees were still disconcerted by this idea. There were, however, other factors at play. Though all but one of the participants knew that birth control pills were used to prevent pregnancy, none of them knew how the pill worked, nor did they know that the pill could also be used to mitigate the severity of cramps or extend time between periods (although, after I explained this, a few commented that they had heard that mentioned somewhere). However, they primarily associated birth control pills with intercourse.

When asked who should use the pill, Mia responded that "sexually active teenagers" should. Similarly, Sophia argued that the pill is for people who are "sexually unrestrained," "provocative girls" (that is, sexual appearance correlates with sexual behavior), and, finally, "prostitutes." Again, we see girls holding onto their innocence and good-girl standing by separating themselves from sexuality as represented by the pill and its users.

While forcefully denying that they would ever take the pill in the near future, again, the girls realized that a future self may. Sophia stated that "I plan on not taking birth control at this point. I might need it for my 
future self, but I'm not going to have sex until I'm married or engaged." She divides her identity and assigns the sexual part to her future self (that is, splintering). Sophia is so frightened by her own sexuality that she cannot even imagine its existence without the framework of a traditional, potentially procreative, and certainly far-off relationship.

My findings contradicted Stubbs' and Johnston-Robledo's hypothesis; my interviewees rejected menstrual suppression through the use of birth control pills. They tried to distance themselves from the position of a sexualized object and the accompanying social and psychological complexities that position forces them to confront. However, this reaction may be complicated by the age of my interviewees and their confusion about the process of menstrual suppression.

Of note is the heteronormativity underlying the imagining of the future self. Supposedly, Sophia would be using the pill to avoid pregnancy, implying that her partner would be male. The same applies to Madison's discomfort with the idea of having "another person inside of me" and categorizing that as a "future Madison problem." She too seems to be invoking a future heterosexual self.

\section{Fear of Rape and Resulting Pregnancy}

One girl, who was not sexually active, expressed concern that she was pregnant because she was a few weeks late in her cycle. She was unaware that irregularity is typical for girls in their first years of menstruation and unclear as to how girls become pregnant. Her anxiety exposes a sense of helplessness and confusion that pervaded the interviews.

While it is evident that adolescent girls resist the sexualization of their bodies, they appear to recognize the choice is not theirs alone. They can abstain from using tampons, the pill, or engaging in sexual activities, but, nevertheless, they perpetually exist under the scrutiny of the male gaze. Their bodies come to signify sexuality for others, if not for themselves. When questioned as to whether she found anything about the onset of her period to be unsettling, Olivia launched into a story in which she recounted: "I know it's kind of gruesome but like people get raped and there was this one girl who was like ten and she had her period and she got raped around the same time that her eggs were releasing and she got pregnant. And that's scary." Apparently, Olivia thought something similar could happen to her. Sophia, in responding to the same prompt, explained: "afterward [after her first period] I had this one concern that I would get raped when I was on my period and then get pregnant ... I think everyone will be scared once they get their first period." Again, we see confusion about the physiology of menstruation as it would be nearly impossible for her to get pregnant when she is in the midst of her period. It is worth exploring whether demystifying the bodily process of menstruation (and sex) would mitigate some of girls' anxieties. However, even if girls did understand menstruation and sex better, it is unlikely this would fully address underlying concerns about lack of control over their new sexual positioning. 
When I first formulated the question about the burdensome aspects of menstrual onset, given prior findings, I had expected answers about cramps or worries about leaking. Rape is a subject that girls in previous studies on menstruation had never broached. At first, I thought this was an isolated event, but a few other girls hinted at the same fear. Additionally, Olivia and Sophia did not go to the same school or know each other. I probed to see whether either could identify the source of this concern, but neither could remember a specific incident. Both also claimed that they had not discussed the topic in health class, nor with parents or teachers. Therefore, I concluded that these statements hint at a subconscious concern over what it means to be a menstruating woman in our society. Reproductive capacity and bodily transformations indicate to others that these girls have developed into sexual beings. As women, their sexuality is influenced and controlled by others, through ideology (in the media, in health class, et cetera) (Garcia 2009; Ward et al. 2019), interpersonal relations (slut-shaming, et cetera) (Armstrong et al. 2014) and, at an extreme, through rape (Valenti 2009). Notably, my interviewees did not worry about rape before menarche, nor did they believe girls who have not begun menstruating needed to worry about it. This is strong evidence of my interpretation of these concerns as representing awareness of insertion into, what Lee (1994) calls, "the dominant patterns of sexuality" (346).

The girls' articulation of this emerging fear was interesting in that they were not simply concerned about being raped, but about being raped and getting pregnant as a result. Pregnancy functions as perhaps the most obvious signal of one's sexuality. This indicates an added layer of apprehension regarding judgment. As the girls consistently noted, they feel they are not the appropriate age for intercourse. Even if they were, female sexuality is still taboo in our culture, and, therefore, a source of shame. Insecure in their sexuality, the girls feared the judgment of others. They wanted to be seen as "good" girls. Thus, while they believed they were more vulnerable to rape after their transition in sexual status, the potential consequences post-menarche seemed to trump the concern of rape itself.

\section{Summary}

My participants made clear the implicit connection between menarche, menstruation, and sexuality as they fluidly transitioned between subjects of menstruation and sex. Girls talked about tampons and Trojans in the same breath, used rhetoric surrounding sex such as "waiting until you are ready" to describe tampon usage, pointed to "provocative girls" as their opposites, and, in one case, feared pregnancy due to irregular cycles. These concerns demonstrated the girls' desire to be "good girls" (that is, asexual), however, their fears of rape and pregnancy highlighted their realization that they exist within a set of gender and power relations; they do not fully control the way their bodies are seen or treated. 


\section{Discussion}

The sexualization of girlhood brings to the fore what Deborah Tolman terms the slut/prude/virgin continuum, whereby behavior, appearance, and morals (the former two supposedly being indicative of the latter) are characterized as existing somewhere between that of a "good girl" and a "slut." Given the pressure to maintain innocence during childhood and fend off the forces of (hyper)sexualization, it is easy to understand why girls may experience trepidation about exiting this space into one of developing sexuality. The particular life stage of these interviewees may help to explain why they were so attached to their self-image as good girls, intimidated by reminders of sexuality, and employed the strategy of splintering.

Sophia most clearly constructed this good girl/bad girl dichotomy. She put a positive value judgment on her sister for wanting to avoid things that reminded her of sex (such as tampons), said that "sexually reckless" girls are the kind of girls who should take the pill, and used her virginity in opposition to the sexuality of the "whore" by saying that she would not take the pill at this point in her life, but "prostitutes" should. In rejecting tampons, the pill, and "provocative girls," my interviewees are investing in the idea of the good girl/virgin. Virginity serves as their form of sexuality and, therefore, strategy to delay dealing with the integration of the sexual self. This is further facilitated by the splintering of the self, which allows them to acknowledge a future sexual self, without needing to resolve the implications of their new social standing.

Labeling itself is an interactional process involving stigma and status (Armstrong et al. 2014). To end up on either extreme of this continuum can result in various formal and informal modes of punishment, though some of the material penalties that may accompany this label, such as rape, are more severe. This process of labeling and related consequences constitutes a form of social control that affects girls' thoughts and behaviors. It is likely that menarche makes real the entrance into these sexual and social relations, and thus discourse on the virgin/whore dichotomy impacts the meaning girls make of this physiological event. Evidencing the impact of this paradigm on their thoughts and behaviors, interviewees themselves reinforced this construct in the way they created a sense of duality between "provocative girls" and themselves. Jessica Valenti (2009) explains that, for girls and women, morality is dependent on sexuality. Thus, in reproducing such dyads, girls claimed their moral superiority and defended their character to the extent possible in the realm of female sexuality.

Such efforts to present themselves as good girls demonstrated interviewees demonstrated internalization of an external gaze. They did not want to appear like "promiscuous" girls and avoided this through choices that served as immediate symbols of their separation from their sexuality. These choices served a deeper hope that these strategies would indicate a societally acceptable form of sexual female character, that is, virginity. However, they realized that this 
self-presentation could only provide so much protection. Roberts (2002), suggested that we can look at the sexualization of girls and women across a continuum and that "...the most extreme act on the continuum of self-objectification is (...) rape" (326-27). Accordingly, my participants revealed their self-objectification and insight into said phenomenon when they cited rape as a potential outcome from their menarcheal transition. Regarding menarche as a transition in sexual status allowed them to make this connection.

Interestingly, my participants were not just concerned by rape itself, but by the potential result: pregnancy. The fear of pregnancy seemed to supersede the fear of rape. Pregnancy is perhaps the most obvious marker of deviant sexuality at this age. For these girls, being labeled a bad girl ranked above the act of rape, demonstrating the extent to which they have internalized a system of value that hierarchizes and reduces them to their gendered sexuality.

\section{Conclusion}

It is important to understand how menarche and menstruation are perceived by adolescent girls because of the immediate impact, long-term consequences, and girls' roles in defining what it means to be a woman/ female. Lee (1994) summarized the broad importance of research on girls' understandings of menarche when she wrote:

Menarche is a physiological happening, framed by the biomedical metaphors of current scientific knowledge, yet also a gendered sexualized happening, a transition to womanhood as objectified other. What is crucial here is that this juncture, menarche, is a site where girls become women and gender relations are produced. Such relations are about power and its absence; power to define the body and live in it with dignity and safety; power to move through the world with credibility and respect. (360)

My interviewees felt the acute shift in their position within gender relations and their lack of power in this moment.

Though my sample was small, the consistency of the packaging of menarche, menstruation, and sexuality across and throughout interviews indicates that this phenomenon is not limited to this group of girls. Contrary to previous work, this study shows that menarche and menstruation are bound up with sexuality in the minds of young adolescent girls. It is likely that the age of the interviewees contributed to these findings. In exiting a space emphasizing childhood innocence, girls are preoccupied with dissociating themselves from sexuality. We see this in the rejection of tampons, birth control, promiscuity, as well as through the use of splintering. Through these methods, girls resist entrance into broader sexual relations where they lose further control of their new bodies. They cling to the image of the good girl, an attempt to hold on to some sense of childhood innocence (that is, asexuality) and to approach teenage sexuality through the safest 
avenue. Nevertheless, these strategies play into the reproduction of the same cultural ideals and power relations that obstruct the development of girls' sexual subjectivity.

Girls' awareness of their reproductive bodies' status as public bodies, and the importance of their appearance as good girls, may further reflect understandings of rape discourse. Specifically, they may internalize the message that rape occurs when girls "ask for it," a message reinforced by rape legislation that often considers the question of who is "rape-able" using idealized notions of female purity (Valenti 2009).

The sexualization of menstruation performed by these girls reveals that this process is problematic not because of the physiological process of menstruation itself but because of the reproductive and sexual implications of menarche and the construction of female sexuality. Future research must explore how the intersection of other identities, such as race and class, relate to the sexualization of menstruation. As intersecting identities alter the construction and experience of female sexuality, so too may they shape the meanings of menarche and the strategies employed to navigate this transition. For this age group in particular, more research into girls' experiences with and understandings of menstruation is required. Further research in this area can inform endeavors to guide girls through this transition in a way that allows them to engage their bodies and sexuality with positivity and ownership. Intervening in this moment may be crucial, not only to regain individual sexual subjectivity, but to redefine womanhood and gendered power relations.

\section{Note}

1. The hymen, or vaginal corona, is actually a membrane that cannot be "broken" and is a permanent, though changing, structure located one to two centimeters inside the vaginal opening (The Swedish Association for Sexuality Education).

\section{REFERENCES}

Armstrong et al. 2014. “'Good Girls': Gender, Social Class, and Slut Discourse on Campus." Social Psychology Quarterly 77 (2): 100-22.

Beausang, Carol C., and Anita G. Razor. 2000. "Young Western Women's Experiences of Menarche and Menstruation." Health Care for Women International 21 (6): 517-528.

The Boston Women's Health Collective. 2011. Our Bodies, Ourselves. New York: Touchstone.

Brooks-Gunn, Jeanne and Diane N. Ruble. 1982. "The Development of Menstrual-Related Beliefs and Behaviors during Early Adolescence." Child Development 53 (6): 1567-77.

Brumberg, Joan Jacobs. 1997. The Body Project: An Intimate History of American Girls. New York: Vintage Books.

Egan, R. Danielle. 2013. Becoming Sexual: A Critical Appraisal of the Sexualization of Girls. Malden, MA: Polity Press. 
Fausto-Sterling, Anne. 2000. Sexing the Body: Gender Politics and the Construction of Sexuality. New York, NY: Basic Books.

Fingerson, Laura. 2006. Girls in Power: Gender, Body, and Menstruation in Adolescence. Albany, NY: State University of New York Press.

Fredrickson, Barbara L. and Tomi-Ann Roberts. 1997. "Objectification Theory: Toward Understanding Women's Lived Experiences and Mental Health Risks.” Psychology of Women Quarterly 21: 173-206.

Garcia, Lorena. 2009. “Now Why Do You Want to Know About That?": Heteronormativity, Sexism, and Racism in the Sexual (Mis)education of Latina Youth." Gender and Society 23 (4): 520-41.

George, Alison, Anne Murcott. 2011. Research Note: Monthly Strategies for Discretion: Shopping for Sanitary Towels and Tampons. The Sociological Review 40 (1): 146-162.

Havens, Beverly and Ingrid Swenson. 1988. "Imagery Associated with Menstruation in Advertising Targeted to Adolescent Women." Adolescence 23 (89): 87-97.

Kessler, Suzanne J. 1990. "The Medical Construction of Gender: Case Management of Intersexed Infants." Signs: Journal of Women in Culture and Society 16 (1): 3-26.

Kissling, Elizabeth Arveda. 1996. “'That's Just a Basic Teen-age Rule': Girls' Linguistic Strategies for Managing the Menstrual Communication Taboo." Journal of Applied Communication Research 24: 292-309.

Koff, Elissa and Jill Rierdan. 1995a. "Early Adolescent Girls' Understanding of Menstruation." Women \& Health 22 (4): 1-19.

-. 1995b. "Preparing Girls for Menstruation: Recommendations from Adolescent Girls." Adolescence 30 (120): 795-811.

Lee, Janet. 1994. "Menarche and the (Hetero)Sexualization of the Female Body." Gender \& Society 8: 343-62.

- 2009. "Bodies at Menarche: Stories of Shame, Concealment, and Sexual Maturation." Sex Roles 60: 615-27.

Maines, Rachel P. 1999. The Technology of Orgasm: "Hysteria," the Vibrator, and Women's Sexual Satisfaction. Baltimore, MD: The Johns Hopkins University Press.

Martin, Karin A. 1996. Puberty, Sexuality, and the Self: Girls and Boys at Adolescence. New York: Routledge.

McPherson, M. E., and L. Korfine. 2004. "Menstruation Across Time: Menarche, Menstrual Attitudes, Experiences, and Behaviors." Women's Health Issues 14: 193-2004.

Moore, Susan M. 1995. "Girls' Understanding and Social Constructions of Menarche." Journal of Adolescence 18(1): 87-104.

Morse, Janice M. and Helen McKinnon Doan. 1987. "Adolescents' Response to Menarche." Journal of School Health 57 (9): 385-89.

Rierdan, J. 1983. "Variations in the Experience of Menarche as a Function of Preparedness." In Menarche: The Transition from Girl to Woman, edited by Sharon Golub, 119-25. Lexington, MA: Lexington Press.

Roberts, Tomi-Ann. 2002. "The Woman in the Body." Feminism \& Psychology 12 (3): 324-29.

Ruble, Diane N. and Jeanne Brooks-Gunn. 1982. "The Experience of Menarche." Child Development 53 (6): 1557-66.

Schooler et al. 2005. "Cycles of Shame: Menstrual Shame, Body Shame, and Sexual Decision-Making." The Journal of Sex Research 42 (4): 324-34. 
Stubbs, Margaret L. and Ingrid Johnston-Robledo. 2013. "Kiddy Thongs and Menstrual Pads: The Sexualization of Girls and Early Menstrual Life." In The Sexualization of Girls and Girlhood: Causes, Consequences, and Resistance, edited by Eileen L. Zurbriggen and Tomi-Ann Roberts, 213-34. New York: Oxford University Press.

Summers-Effler, Erika. 2004. "Little Girls in Women's Bodies: Social Interaction and the Strategizing of Early Beast Development." Sex Roles 51 (1/2): 29-44.

The Swedish Association for Sexuality Education. The Vaginal Corona. Translated by Jonas Hartelius. Stockholm: RFSU. https://www.rfsu.se/globalassets/pdf/vaginal-corona-english.pdf

Thorne, Barrie. 1994. Gender Play: Girls and Boys in School. New Brunswick, NJ: Rutgers University Press.

Tolman, Deborah et al. 2015. "Mobilizing Metaphors: Considering Complexities, Contradictions, and Contexts in Adolescent Girls' and Young Women's Agency." Sex Roles 73: 298-310.

Valenti, Jessica. 2009. The Purity Myth: How America's Obsession with Virginity Is Hurting Young Women. Berkeley, CA: Seal Press.

Ward et al. 2019. "Following Their Lead? Connecting Mainstream Media Use to Black Women's Gender Beliefs and Sexual Agency." The Journal of Sex Research: $1-13$.

Whisnant, Lynn, and Leonard Zegans. 1975. "A Study of Attitudes toward Menarche in White Middle-Class American Adolescent Girls." American Journal of Psychiatry 132 (8): 809-814.

Zurbriggen et al. 2007. Executive Summary: APA Task Force on the Sexualization of Girls. Washington, DC: American Psychological Association.

Open Access This chapter is licensed under the terms of the Creative Commons Attribution 4.0 International License (http://creativecommons.org/licenses/ by/4.0/), which permits use, sharing, adaptation, distribution and reproduction in any medium or format, as long as you give appropriate credit to the original author(s) and the source, provide a link to the Creative Commons license and indicate if changes were made.

The images or other third party material in this chapter are included in the chapter's Creative Commons license, unless indicated otherwise in a credit line to the material. If material is not included in the chapter's Creative Commons license and your intended use is not permitted by statutory regulation or exceeds the permitted use, you will need to obtain permission directly from the copyright holder.

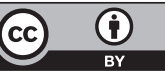

